\title{
$\begin{array}{ll}\text { Research Square } & \text { Preprints are preliminary reports that have not undergone peer review. } \\ \text { They should not be considered conclusive, used to inform clinical practice, } \\ \text { or referenced by the media as validated information. }\end{array}$
}

\section{Implementation of infection prevention and control components in 1,442 hospitals in the Republic of Korea: evaluation using the WHO Infection Prevention and Control Assessment Framework (IPCAF)}

Yoolwon Jeong ( $\nabla$ yoolwon@gmail.com )

Ministry of Health and Welfare, Republic of Korea

Hyeyoung Joo

Ministry of Health and Welfare, Republic of Korea

Hyunjung Bahk

Korea Disease Control and Prevention Agency

Hyunsuk Koo

Korea Disease Control and Prevention Agency

Hyungmin Lee

Korea Disease Control and Prevention Agency

Kinam Kim

Korea Disease Control and Prevention Agency

\section{Research Article}

Keywords: Infection control, survey, COVID-19, Republic of Korea

Posted Date: January 21st, 2022

DOI: https://doi.org/10.21203/rs.3.rs-1272628/v1

License: (c) (i) This work is licensed under a Creative Commons Attribution 4.0 International License.

Read Full License 


\section{Abstract}

Background: The current epidemic of coronavirus disease 2019 continues to underscore the inadequacy of infection prevention and control (IPC) and the importance of its sound establishment in healthcare facilities. The Infection Prevention and Control Assessment Framework (IPCAF), developed by the World Health Organization, allows systematic assessment of IPC capacity in healthcare facilities and was therefore applied in many national-level surveys. This study aims to assess the IPC capacity of Korean hospitals as well as their strengths and pitfalls, by analyzing the results of the first nationwide IPC survey, using the IPCAF frame.

Methods: The Korean National Infection Prevention and Control Survey (KNIPCS) was conducted from February to March 2018. As the survey preceded the release of IPCAF, the survey questionnaire was developed through a series of expert consultations. Although the KNIPCS did not directly apply the IPCAF, its contents complied with the IPCAF to a large extent to allow exploration of its results with regards to IPCAF. The survey questionnaire was distributed to a total of 2,108 hospitals.

Results: A total of 1,442 hospitals completed the survey with a response rate of $68.4 \%$. All tertiary hospitals and the majority of general hospitals had implemented IPC teams and programs, whereas the percentage was lower for smaller-sized hospitals and long-term care hospitals. A similar trend was observed for surveillance and IPC practice monitoring activities. The percentage of interactive IPC training was lower than $30 \%$ in all hospital groups. While activities and guidelines were frequently applied for activities such as disinfection and, activities regarding antimicrobial resistance were relatively weak in all hospital groups except for tertiary hospitals.

Conclusions: In general, essential IPC structures, such as IPC teams and programs, were well in place in most tertiary and general hospitals in Korea. These hospital groups also more actively performed various IPC activities. As most previous legislative and multimodal policy measures have targeted these hospital groups, we have speculated that future policy efforts should encompass long-term care hospitals and smaller-sized hospitals to strengthen the IPC capacity of these hospital groups. Efforts should also be put forth to promote IPC training and antimicrobial activities.

\section{Background}

Healthcare-associated infection (HCAI) and infection prevention and control (IPC) have emerged as one of the most significant public health issues worldwide. Meanwhile, the current epidemic of coronavirus disease 2019 (COVID-19) is underscoring the inadequacy of IPC and the importance of its sound establishment in healthcare facilities. For optimal and timely administration of IPC practices in disease outbreak situations, a dedicated team of IPC specialists and a facility-level IPC program should be up and running in advance. It is evident that these essential IPC structures are critical to secure basic IPC in facilities and guarantee minimum protection to its patients and staff [1]. Since 2019, World Health 
Organization (WHO) has recommended IPC teams and in-facility IPC programs as one of the core components in IPC [2], and again highlighted its significance in the COVID-19 IPC guidance in 2021 [3].

In Korea, despite the advancement in medical technology and quality of healthcare services, HCAI has also evolved into a serious health concern with a significant socioeconomic burden [4]. In response to such increased public concern, a series of relevant policies and strategies have been rolled out to strengthen healthcare facilities' capacity in IPC. These policy measures included legislative approaches which mandated hospitals to operate IPC teams and programs, as well as various quality-driven approaches such as improvement in systems and built environment, positive reinforcement through incentives and reimbursement, and performance evaluation programs, among others [5]. In early 2018, the government conducted the Korean National Infection Prevention and Control Survey (KNIPCS) 2018 as a means to gain a detailed picture of the extent to which IPC structures and capacity were strengthened in Korean hospitals as a result of these policy measures.

In September 2018, WHO released the Infection Prevention and Control Assessment Framework (IPCAF) which is a structured tool that allows systematic assessment of IPC capacity in healthcare facilities [6]. It is based on the "Guidelines on Core Components of Infection Prevention and Control Programmes", and thus consists of questionnaires pertaining to each core component (CC) of the guideline. The tool is primarily intended to be used as a self-assessment by facilities, but can also be used for the purpose of joint assessment between an external assessor and the facility. Accordingly, analysis of nationwide assessments and inter-country comparisons using the IPCAF were incorporated in numerous previous studies, which have provided valuable insights [7-8]. Although the KNIPCS did not directly apply the IPCAF questionnaire, its contents comply with the IPCAF to a large extent to allow exploration of its results with regards to IPCAF. This study aims to assess the IPC structure and program of Korean hospitals as well as their strengths and pitfalls, by analyzing the results of the KNIPCS using the WHO IPCAF frame.

\section{Methods}

The KNIPCS was conducted from February to March 2018 by the Ministry of Health and Welfare and the Korea Disease Control and Prevention Agency. As the questions in the survey were developed to examine the status of IPC in hospital-level institutions, the survey targeted hospitals only and excluded clinic-level institutions. The survey questionnaire was distributed to a total of 2,108 hospitals. A survey focal point in respective hospitals was provided an access link to the survey webpage into which they entered the answers of each questionnaire. Participation was on a voluntary basis.

The execution of the national survey is in accordance with article 17 of the Infectious Disease Control and Prevention Act, which stipulates the role of the government to conduct surveys regarding the conditions and status of infection control. As the survey did not include any individual human data, ethics approval was waivered. Nevertheless, data was collected and analyzed by a third party, a statistical analysis company contracted prior to the initiation of the survey, in order to ensure privacy and data protection. 
The types of hospitals that had participated in the survey include 'hospitals, 'general hospitals', 'tertiary hospitals', and 'long-term care hospitals', the definitions of which are based on the Korean Medical Service Act. Here, 'hospital' refers to healthcare facilities with more than 30 beds providing mostly inpatient services. A 'general hospital' refers to hospitals with more than 100 beds and at least 7 to 9 specialized departments. Among these general hospitals, the Minister of Health and Welfare designates 'tertiary hospitals' which are training hospitals with at least 20 specialized departments. 'Long-term care hospitals' refer to hospitals providing medical services to inpatients in need of long-term care.

The survey questionnaire was developed by the government via expert consultations. The expert group consisted of medical doctors and registered nurses with expertise in infection control. The development of the survey questionnaire was largely based on the IPC standards stipulated in the Korean Medical Service Act, which is the law regulating duties and responsibilities of medical institutions in Korea. For example, the Act stipulates the required number of full-time IPC specialists, the structure of the IPC committee, and compulsory training of IPC specialists, etc. After rounds of expert discussions, the survey questionnaire was developed to encompass 9 components which are: (1) IPC teams and programs, (2) IPC committees, (3) IPC costs and expenditures, (4) IPC training and education, (5) IPC surveillance, (6) Staffing, (7) Equipment and built environment, (8) IPC activities, and (9) IPC activities to prevent Antimicrobial resistance. IPCAF, on the other hand, is composed of 8 sections and a total of 81 indicators. Each indicator is associated with scores based on the answers chosen and ultimately added up to yield an aggregate score of each component as well as an overall score. As the KNIPCS questionnaire is not identical to the IPCAF in its structure and scoring system, their direct comparison of attained scores is not possible. However, there are common individual indicators included in both surveys, allowing comparison of the results on an indicator level. The structure of the national survey in comparison with WHO IPCAF is presented in Table 1.

\section{Results}

A total of 1,442 hospitals completed the survey, with a response rate of $68.4 \%$. The general characteristics of the participating hospitals are provided in Additional file 1. Concerning CC1, all tertiary hospitals and the majority of general hospitals had an IPC committee as well as an IPC team with at least one full-time IPC professional [Table 2]. Among hospitals, 112 (67.0\%) had at least one full-time IPC professional and $56(33.5 \%)$ had an IPC program. The average number of IPC staff in tertiary hospitals was 4.7 for doctors and 7.3 for nurses. General hospitals had on average 1.6 doctors and 2.2 nurses in the IPC team. In tertiary hospitals and general hospitals, more than $80 \%$ of IPC training (CC3) was provided by oral instruction, whereas interactive methods were used much less frequently. Doctors in the IPC team received more than 20 hours of ongoing education and nurses received more than 40 hours on average in both tertiary hospitals and general hospitals.

All 42 tertiary hospitals were participating in the Korean National Healthcare-associated Infections Surveillance (KONIS), whereas 90 general hospitals (34.6\%) and the majority of hospitals and long-term care hospitals did not [Table 3]. Profound differences were revealed concerning surveillance activities 
among hospital types, as most of the tertiary hospitals (97.6\%) and general hospitals (73.8\%) were performing prioritization of HCAl and risk factors to be targeted for surveillance, whereas only $29.9 \%$ of hospitals were doing so. All tertiary hospitals and the majority of general hospitals were performing surveillance on surgical site infection (SSI), bloodstream infections, urinary tract infections, and pneumonia, all of which are a part of the KONIS. With regard to CC6, hand hygiene and disinfection/sterilization were frequently monitored across all hospital types. Monitoring of transmissionbased precautions and multi-drug resistant (MDR) pathogen screening were much less frequently conducted. Among tertiary hospitals, 35(83.3\%) performed MDR pathogen surveillance screening before patients were admitted to the intensive care unit (ICU), whereas only $128(57.7 \%)$ of general hospitals did so.

All tertiary hospitals had guidelines available for antibiotic stewardship, disinfection and sterilization and environmental cleaning [Table 4]. The majority of general hospitals ( $\geq 95 \%)$ also had these guidelines available, with the exception of antibiotic stewardship (65.7\%). Regarding guidelines for disinfection and sterilization $123(73.6 \%)$ hospitals and $889(91.3 \%)$ long-term care hospitals had them available. With regards to CC8, the average number of patients sharing a hand hygiene station were the smallest in tertiary hospitals ( 1.6 persons) and the largest in long-term care hospitals (6.8 persons). Regarding the area where fluids and/or injections are prepared before admission to patients, 4(9.5\%) tertiary hospitals, 84(32.3\%) general hospitals, and 479(49.3\%) long-term care hospitals prepared them in areas other than a sterile compound or a dedicated preparation area.

\section{Discussion}

In general, the results of this study show that essential IPC structures, such as IPC teams and programs, are well in place in most tertiary and general hospitals in Korea. This may be partly owing to relevant legislative measures, such as the Korean Medical Service Act, which mandated the operation of an IPC committee and an IPC team in all general hospitals and hospitals with more than 150 beds. All long-term care hospitals and hospitals with less than 150 beds are not subject to the mandatory implementation of IPC teams, which may also explain the relatively low rate of IPC teams in these hospital groups. Studies show that countries with similar legislative regulations have a more robust implementation of IPC structures compared to countries that do not, suggesting that the influence of relevant legislature is critical in the establishment of IPC components in healthcare facilities [7-8].

Nevertheless, such legislative measures were coupled with various policy measures to promote the quality of care in IPC. Implementation of IPC programs was included or expanded in performance evaluation programs such as the Korean Healthcare Accreditation System and Healthcare quality evaluation. Under the National Health Insurance, a novel reimbursement scheme was developed in 2016 that pays hospitals a certain amount of fee per patient's admission day, provided that the hospital meets specified criteria which includes: operation of an IPC team with a designated number of full-time, trained IPC staff and development of IPC program, etc. It is assumed that a combined effect of legislation and 
such quality-driven approaches have resulted in a generally high percentage of IPC teams and programs in tertiary and general hospitals in Korea.

Much evidence shows that an IPC structure, composed of a dedicated IPC team and relevant in-house governance, reduces HCAls and is thus the single most important component in an institution's IPC capacity [9-10]. However, it is interesting to note that despite the high percentage of hospitals with an established IPC team and committee, their actual operation was quite heterogeneous and suboptimal in many hospitals, implying that the installation of these IPC structures does not instantly guarantee effective execution of IPC activities. One example is shown through the data on the IPC committee meeting, which is a decision-making process concerning IPC policies in hospitals. However, 87 (33.4\%) general hospitals held two or fewer committee meetings per year and 23(8.8\%) answered that committee meetings were not helpful in the actual implementation of IPC programs in the facility (Additional file 2). Similar results were revealed in another study, in which $23 \%$ of hospitals answered that the IPC committee was not supported by senior staff [8].

IPC education and training is proven to be effective in reducing HCAl if conducted in the right approach to achieve behavior change [11-13]. In addition, as IPC is relevant to all healthcare workers, IPC education has to target not only the IPC specialists and frontline workers but also all general staff in the facility. Results of this study reveal that IPC education targeting IPC specialists was one of the components with generally high compliance, possibly owing to the Korean Medical Service Act that stipulates mandatory education of at least 16 hours to members of the IPC team. On the other hand, IPC education targeting all general staff in the facility shows room for improvement, especially in its mode of training. A simple, oneway oral instruction was more frequently applied compared to interactive training in all hospital groups. Previous studies conducted among hospitals in Austria and Germany also showed that interactive training was the least utilized mode of training [7-8]. This implies that future policies should aim to strengthen interactive learning and other modes of effective training.

HCAI surveillance (CC4) of Korea centers around KONIS, which is the government-led surveillance program in which hospitals participate on a voluntary basis. The structure of KONIS is quite complex and beyond the scope of this study, but mainly consists of an ICU and an SSI surveillance [14]. KONIS ICU survey includes surveillance of bloodstream infections, urinary tract infections, and pneumonia, which explains the relatively high surveillance percentage in these categories in the tertiary and general hospital groups. KONIS applies standardized data collection methods (IPCAF CC4 question 9), informatics (IPCAF CC4 question 4), protocols (IPCAF CC4 question 8), audit processes (IPCAF CC4 question 10), uniform data feed-back methods (IPCAF CC4 question 14), and governance (IPCAF CC4 question 3), which all participating hospitals share. However, only a limited number of hospitals in the hospital and long-term care hospital group participated in the KONIS, revealing the need to expand IPC surveillance in these hospital groups. The government is currently in the process of developing adequate surveillance modules for smaller-sized hospitals and long-term care hospitals [15]. 
While CC2 was a component with high mean scores in studies from other countries, this study revealed different results. Guideline for disinfection and sterilization was the most commonly available IPC guideline in all hospital types, which may be contributing to the relatively high percentage of hospitals monitoring disinfection and sterilization. On the other hand, the percentage of hospitals with antibiotic stewardship guidelines was quite low, especially in the hospitals (51.5\%) and long-term care hospital group (31.0\%). This result along with the relatively low percentage of hospitals performing MDR pathogen screening and isolation of MDR-positive patients reveal that antimicrobial resistance activities in these hospital groups are suboptimal. Many previous studies have raised issues regarding the relatively high prevalence of MDR pathogens in smaller-sized hospitals [16-17]. While implementation of antibiotic stewardship programs is being considered essential in all healthcare institutions [18], this result calls for more active policy support in this area.

The questions in the national survey relevant to CC7 and CC8 of IPCAF generally did not match those in IPCAF to allow precise comparison of its results. Staffing levels (CC7) and most indicators under CC8, such as water supplies and ventilation, are basic facility requirements and thus were not included in the national survey. Nonetheless, several indicators which are original to the national survey are worth mentioning. Hand hygiene stations were generally accessible to all patients but the number of patients per station was especially high in long-term care hospitals compared to other hospital groups. Not all of the general hospitals in the country were equipped with isolation rooms in emergency rooms. Such insufficiency in the built environment has been an issue in other high-income countries as well [19], underscoring the need for continued policy support in establishing the basic infrastructure in healthcare facilities.

Fluid and injections were prepared in areas other than clean rooms and dedicated preparation areas in $32.3 \%$ of general hospitals and $49.3 \%$ of long-term care hospitals. As more strict measures are being taken around the world regarding the preparation of pharmaceuticals in hospitals, national-level policy measures should be developed and implemented to prevent potential hazards stemming from contamination of fluids and other pharmaceuticals [20].

Implementation of multimodal strategies (CC5) was not effectively surveyed through the national survey. However, reflecting that $\mathrm{CC} 5$ was the component with the lowest mean score in other high-income countries [7-8], it could be speculated that Korean hospitals may also have similar difficulties in the effective implementation of multimodal strategies. Whereas individual elements of multimodal strategies, e.g. education and training, could already be at work, systematically integrating them to achieve behavioral change requires a certain level of expertise in the field. Policy measures should be put forth to strengthen facilities in delivering multimodal strategies. It is also advisable that future national surveys incorporate CC5 indicators to allow speculation of its status in hospitals.

This study has several limitations. First of all, the national survey was on a voluntary basis and therefore facilities with a high interest in IPC may be overrepresented. In addition, as the answers were selfadministered, data can be different from other currently available national-level data sets, such as the 
national health insurance data. Lastly, although many of the survey questions were similar to its IPCAF counterparts, the answering options were different and therefore hampered direct comparison.

\section{Conclusions}

The first-ever nationwide survey of IPC and the evaluation of its results using WHO IPCAF revealed an overview of IPC status in Korean hospitals and provided valuable policy insights. The establishment of a basic IPC structure, such as full-time IPC staff and IPC programs, is generally high in tertiary hospitals and general hospitals, which is speculated to be the effect of both legislative and quality-based policy measures in IPC. The establishment of the IPC structure was relatively weak in long-term care hospitals and smaller-sized hospitals, which call for future policy efforts targeting these hospital groups. Although hospitals were actively conducting the individual elements of multimodal strategies, whether they are implemented in a coordinated and systematic manner should be more actively explored in future surveys.

\section{Abbreviations}

IPC: Infection prevention and control; IPCAF: Infection Prevention and Control Assessment Framework; KNIPCS: The Korean National Infection Prevention and Control Survey; HCAl: Healthcare-associated infection; COVID-19: Coronavirus disease 2019; WHO: World Health Organization; CC: Core components; KONIS: Korean National Healthcare-associated Infections Surveillance; SSI: Surgical site infection; MDR: Multi-drug resistant, ICU: Intensive care unit

\section{Declarations}

\section{Ethics approval and consent to participate}

Ethics approval was waived for this survey, because the development of the questionnaire and collection of data was in full alignment with the Korean Medical Service Act.

\section{Consent for publication}

Not applicable.

\section{Availability of data and materials}

All relevant data and material are included in the main text and the supplementary information files of this manuscript.

\section{Competing interests}

The authors declare that they have no competing interests. 


\section{Funding}

All authors report no financial support relevant to this manuscript.

\section{Authors' contributions}

YJ wrote the original draft of the manuscript. $\mathrm{HJ}, \mathrm{HB}, \mathrm{HK}, \mathrm{HL}$ participated in the questionnaire development and data collection. YJ and KK designed the analysis. All authors read, edited, and approved the final manuscript.

\section{Acknowledgements}

The authors wish to thank all of the participants of the national survey for their valuable input and the group of specialists who had participated in the development of the survey questionnaire as well as data collection for their effort.

\section{References}

1. Storr J, Twyman A, Zingg W, Damani N, Kilpatrick C, et al. Core components for effective infection prevention and control programmes: new WHO evidence-based recommendations. Antimicrob Resist Infect Control 2017; 6:6. doi: 10.1186/s13756-016-0149-9. eCollection 2017.

2. Guidelines on core components of infection prevention and control programmes at the national and acute health care facility level. Geneva: World Health Organization; 2016.

3. Infection prevention and control healthcare facility response for COVID-19. Interim guidance. Geneva: World Health Organization; 2020.

4. Song J, Kim S, Kim KM, Choi SJ, Oh HS, Park ES, et al. Prospective estimation of extra health care costs and hospitalization due to nosocomial infections in Korean Hospitals. Korean $\mathrm{J}$ healthc assoc Infect Control Prev 1999;4:157-65.

5. Jeong Y, Kim K. A Comparative Analysis of Healthcare-Associated Infection Policy in South Korea and Its Implications in Coronavirus Disease 2019. J health policy manag 2021;31(3):312-327. doi: https://doi.org/10.4332/KJHPA.2021.31.3.327.

6. Infection Prevention and Control Assessment Framework: World Health Organization; 2018. https://www.who.int/publications/i/item/WHO-HIS-SDS-2018.9. PDF. Accessed 24 Oct 2021.

7. Aghdassi S, Hansen S, Bischoff P, Behnke M, Gastmeier P. A national survey on the implementation of key infection prevention and control structures in German hospitals: results from 736 hospitals conducting the WHO Infection Prevention and Control Assessment Framework (IPCAF). Antimicrob Resist Infect Control 2019 May 8;8:73. doi: 10.1186/s13756-019-0532-4. 
8. Aghdassi S, Grisold A, Wechsler-Fördös A, Hansen S, Bischoff P, et al. Evaluating infection prevention and control programs in Austrian acute care hospitals using the WHO Infection Prevention and Control Assessment Framework. Antimicrob Resist Infect Control 2020 Jun 22;9(1):92. doi: 10.1186/s13756-02000761-2.

9. Haley RW, Culver DH, White JW, Morgan WM, Emori TG, Munn VP, et al. The efficacy of infection surveillance and control programs in preventing nosocomial infections in US hospitals. Am J Epidemiol. 1985;121(2):182-205.

10. Zingg W, Holmes A, Dettenkofer M, Goetting T, Secci F, Clack L, et al. Hospital organisation, management, and structure for prevention of health-care-associated infection: a systematic review and expert consensus. Lancet Infect Dis. 2015;15(2):212-24. doi: 10.1016/S1473-3099(14)70854-0.

11. Viana WN, Bragazzi C, Couto de Castro JE, Alves MB, Rocco JR. Ventilator-associated pneumonia prevention by education and two combined bedside strategies. Int J Qual Health Care. 2013;25(3):308-13. doi: $10.1093 /$ intqhe/mzt025.

12. Turnberg W, Daniell W, Simpson T, Van Buren J, Seixas N, Lipkin E, et al. Personal healthcare worker $(\mathrm{HCW})$ and work-site characteristics that affect HCWs' use of respiratory-infection control measures in ambulatory healthcare settings. Infect Control Hosp Epidemiol. 2009;30(1):47-52. doi: 10.1086/592707.

13. Rosenthal VD, McCormick RD, Guzman S, Villamayor C, Orellano PW. Effect of education and performance feedback on handwashing: the benefit of administrative support in Argentinean hospitals. Am J Infect Control. 2003;31(2):85-92. doi: 10.1067/mic.2003.63.

14. Choi Y. Prospective nationwide healthcare-associated infection surveillance system in South Korea. J Korean Med Assoc 2018;61(1):21-25. doi: https://doi.org/10.5124/jkma.2018.61.1.21

15. Ministry of Health and Welfare, Republic of Korea. National Policy for Prevention and Management of Healthcare-associated Infection 2018-2022. [cited 11 Jul 2021]. Available from:

http://www.mohw.go.kr/react/al/sal0301vw.jsp?

PAR_MENU_ID =04\&MENU_ID=0403\&page=1\&CONT_SEQ $=345237$

16. Liu C, Yoon E, Kim D, Shin J, Shin K, et al. Antimicrobial resistance in South Korea: A report from the Korean global antimicrobial resistance surveillance system (Kor-GLASS) for 2017. J Infect Chemother 2019;25(11):845-859. doi: https://doi.org/10.1016/j.jiac.2019.06.010

17. Park J, Seo Y, Kim S, Park H, Eom J, et al. Incidence of Catheter-associated Urinary Tract Infection in Hospitals with Less than 300 Beds. Korean J Healthc Assoc Infect Control Prev 2019;24(1):11-18. doi: https://doi.org/10.14192/kjhaicp.2019.24.1.11

18. Policy statement on antimicrobial stewardship by the Society for Healthcare Epidemiology of America (SHEA), the Infectious Diseases Society of America (IDSA), and the Pediatric Infectious Diseases Society 
(PIDS). Infect Control Hosp Epidemiol 2012;33:322e7.

19. Struelens MJ, Wagner D, Bruce J, MacKenzie FM, Cookson BD, Voss A, et al. Status of infection control policies and organisation in European hospitals, 2001: the ARPAC study. Clin Microbiol Infect. 2006;12(8):729-37. doi: 10.1111/j.1469-0691.2006.01462.x.

20. Jackson CA, Wison DA. World at work: Hospital pharmacy clean-rooms. Occup Environ Med. 2006 Jan; 63(1): 68-70. doi: 10.1136/oem.2005.020719

\section{Tables}

Table 1. Structure of the Korean national IPC survey in comparison with WHO IPCAF 
WHO IPCAF Section (Core component)

Core component 1 . IPC program (10 indicators)

Core component 2. IPC guidelines (8 indicators)

Core component 3. IPC education and training (10 indicators)

Core component 4 . Healthcareassociated infection surveillance ( 15 indicators)

Korean national IPC survey questions that correlate with indicators in each section of WHO IPCAF

- Availability of an IPC team

- Availability of an IPC committee

- Availability of an IPC program

- Availability of at least one full-time IPC professional or equivalent ${ }^{\star}$

- Membership of an IPC team (Inclusion of doctors, nurses, etc.)

- Structure and operation of the IPC committee

- Availability of a guideline for: environmental cleaning, transmission-based precautions, disinfection and sterilization, antibiotic stewardship, etc.

- Availability of personnel to lead IPC training

- Mode of IPC training ${ }^{\dagger}$

- Availability of ongoing education for IPC staff

- Inclusion of HCAl surveillance in IPC program

- Availability of personnel responsible for HCAI surveillance

- Prioritization of HCAl to be targeted for surveillance

- Surveillance conducted for: Surgical site infections, device-associated infections, MDR pathogens, etc.

Core component 5. Multimodal strategies for implementation of IPC interventions (5 indicators)

Core component 6 . Monitoring/audit of IPC practices and feedback (8 indicators)

- Inclusion of education and training in IPC programs

- Discussions of system change (infrastructure, manpower, internal regulations, etc. $)^{\ddagger}$

- Availability of personnel to conduct monitoring/audit

- Processes monitored: hand hygiene, intravascular catheter insertion, activities to prevent MDR pathogens, disinfection and sterilization

Core component 7. Workload, staffing and bed occupancy (8 indicators)

Core component 8. Built environment, materials, and equipment for IPC at the facility level (17 indicators)
- Staffing levels

- Bed occupancy (spacing, one patient per bed, etc.)

- Availability of materials and supplies (personal protection equipments, disposable items, etc.)

- Availability of isolation rooms

- Availability of hand hygiene stations 
IPC, Infection Prevention and Control; WHO, World Health Organization; IPCAF, Infection Prevention and Control Assessment Framework, MDR, Multi-drug resistant; $H C A l$, Healthcare-associated infection. ${ }^{*} \mathrm{~A}$ nurse or doctor working $100 \%$ in IPC, 'Using written information, oral instruction, e-learning, interactive training, etc., ${ }^{\ddagger}$ However, in the Korean National Infection Prevention and Control survey, these questions were not addressed as a part of a "multimodal strategy" as defined in the WHO IPCAF, but as an independent indicator.

Table 2. Results of the Korean national IPC survey corresponding to CC1 and CC3 of WHO IPCAF

\begin{tabular}{|c|c|c|c|c|c|}
\hline \multirow{3}{*}{$\begin{array}{l}\text { Korean national IPC survey } \\
\text { questions }\end{array}$} & \multirow[t]{3}{*}{ Answer } & \multicolumn{4}{|c|}{ Number (\%) } \\
\hline & & $\begin{array}{l}\text { Tertiary } \\
\text { hospital }\end{array}$ & $\begin{array}{l}\text { General } \\
\text { hospital }\end{array}$ & & $\begin{array}{l}\text { Long- } \\
\text { term care }\end{array}$ \\
\hline & & $(n=42)$ & $(n=260)$ & & $(n=973)$ \\
\hline
\end{tabular}

Corresponding IPCAF core component : Core Component 1 (IPC program)

\begin{tabular}{|c|c|c|c|c|c|}
\hline Availability of an IPC team & Yes(Available) & $42(100.0)$ & $251(96.5)$ & $37(22.1)$ & $62(6.3)$ \\
\hline $\begin{array}{l}\text { Availability of an IPC } \\
\text { committee }\end{array}$ & Yes(Available) & $42(100.0)$ & $257(98.8)$ & $64(38.3)$ & $704(72.4)$ \\
\hline \multirow{3}{*}{$\begin{array}{l}\text { Number of IPC committee } \\
\text { meetings held per year }\end{array}$} & $0 \sim 1$ & $0(0.0)$ & $4(1.6)$ & $6(9.4)$ & $35(5.0)$ \\
\hline & 2 & $6(14.3)$ & $83(32.3)$ & $22(34.4)$ & $296(42.0)$ \\
\hline & $\begin{array}{l}3 \text { times or } \\
\text { more }\end{array}$ & $36(85.7)$ & $170(65.3)$ & $36(21.5)$ & $373(38.3)$ \\
\hline Availability of an IPC program & Yes(Available) & $42(100.0)$ & $249(95.8)$ & $56(33.5)$ & $745(76.6)$ \\
\hline $\begin{array}{l}\text { Availability of at least one full- } \\
\text { time IPC professional }\end{array}$ & $\begin{array}{l}\text { Full-time IPC } \\
\text { nurse }\end{array}$ & $42(100.0)$ & $255(98.1)$ & $112(67.0)$ & DNA \\
\hline \multirow{2}{*}{$\begin{array}{l}\text { Average number of doctors } \\
\text { and nurses in the IPC team } \\
\text { (number) }\end{array}$} & Doctors & 4.74 & 1.66 & 0.91 & 0.68 \\
\hline & Nurses & 7.31 & 2.23 & 0.95 & 1.00 \\
\hline
\end{tabular}

Core Component 3 (IPC education and training)

\begin{tabular}{llllll|}
$\begin{array}{l}\text { Mode of IPC training } \\
\text { (percentage to total number of } \\
\text { training sessions, multiple } \\
\text { answers allowed) }\end{array}$ & $\begin{array}{l}\text { oral } \\
\text { instruction }\end{array}$ & 88.9 & 86.7 & 77.0 & 61.6 \\
\cline { 2 - 6 } & e-learning & 9.8 & 9.5 & 13.9 & 37.2 \\
\cline { 2 - 6 } & interactive & 25.2 & 14.9 & 8.1 & 12.3 \\
\hline $\begin{array}{l}\text { Ongoing education for IPC } \\
\text { staff (average hours of } \\
\text { received education per year) }\end{array}$ & Doctors & 21.67 & 21.26 & 5.20 & 6.57 \\
\cline { 2 - 6 } & Nurses & 44.82 & 46.10 & 12.97 & 12.15 \\
\hline
\end{tabular}


IPC, Infection Prevention and Control; $C C$, Core component; WHO, World Health Organization; IPCAF, Infection Prevention and Control Assessment Framework; DNA, Data not available.

Table 3. Results of the Korean national IPC survey corresponding to CC4 and CC6 of WHO IPCAF

\begin{tabular}{|c|c|c|c|c|c|}
\hline \multirow{2}{*}{$\begin{array}{l}\text { Korean national IPC survey } \\
\text { questions }\end{array}$} & \multirow[t]{2}{*}{ Answer } & \multicolumn{4}{|c|}{ Number (\%) } \\
\hline & & $\begin{array}{l}\text { Tertiary } \\
\text { hospital } \\
(n=42)\end{array}$ & $\begin{array}{l}\text { General } \\
\text { hospital } \\
(n=260)\end{array}$ & $\begin{array}{l}\text { Hospital } \\
(n=167)\end{array}$ & $\begin{array}{l}\text { Long- } \\
\text { term care } \\
\text { hospital } \\
(\mathrm{n}=973)\end{array}$ \\
\hline
\end{tabular}

Corresponding IPCAF core component : Core Component 4 (HCAI surveillance)

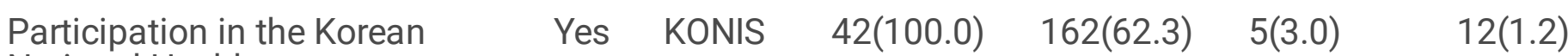

National Healthcare-

associated Infections

Surveillance (KONIS)

ICU

survey

KONIS 42(100.0) 155(59.6) 5(3.0) 5(0.5)

SSI

survey

\begin{tabular}{|c|c|c|c|c|c|}
\hline & No & none & $90(34.6)$ & $160(95.8)$ & $957(98.4)$ \\
\hline $\begin{array}{l}\text { Prioritization/identification of } \\
\text { HCAl and risk factors to be } \\
\text { targeted for surveillance }\end{array}$ & Yes & $41(97.6)$ & 192(73.8) & $50(29.9)$ & $383(39.4)$ \\
\hline \multirow[t]{4}{*}{ Surveillance conducted for: } & SSI & $42(100.0)$ & $176(69.6)$ & $77(57.0)$ & $46(4.9)$ \\
\hline & $\begin{array}{l}\text { Bloodstream } \\
\text { infections }\end{array}$ & $42(100.0)$ & 206(81.4) & $40(29.6)$ & $114(12.1)$ \\
\hline & $\begin{array}{l}\text { Urinary tract } \\
\text { infections }\end{array}$ & 42(100.0) & $216(85.4)$ & $46(34.1)$ & $238(25.2)$ \\
\hline & Pneumonia & $42(100.0)$ & $205(81.0)$ & $51(37.8)$ & 196(20.7) \\
\hline
\end{tabular}

Core Component 6 (Monitoring/audit of IPC practices and feedback)

\begin{tabular}{|c|c|c|c|c|c|}
\hline \multirow[t]{4}{*}{ IPC practices monitored: } & Hand hygiene & $41(97.6)$ & 235(92.9) & $121(89.6)$ & 935(98.8) \\
\hline & $\begin{array}{l}\text { MDR } \\
\text { pathogen } \\
\text { screening* }\end{array}$ & 35(83.3) & $128(57.7)$ & $5(25.0)$ & $4(25.0)$ \\
\hline & $\begin{array}{l}\text { Disinfection } \\
\text { and } \\
\text { sterilization }^{\dagger}\end{array}$ & $42(100.0)$ & $253(97.3)$ & 108(64.7) & $830(85.3)$ \\
\hline & $\begin{array}{l}\text { Isolation of } \\
\text { MDR positive } \\
\text { patients }\end{array}$ & $42(100.0)$ & 207(93.2) & 12(70.6) & $6(54.5)$ \\
\hline
\end{tabular}


IPC, Infection Prevention and Control; $C C$, Core component; WHO, World Health Organization; IPCAF, Infection Prevention and Control Assessment Framework; HCAl, Healthcare-associated infection; ICU, Intensive care unit; $S S I$, Surgical site infection; DNA, Data not available. "MDR pathogen surveillance screening before ICU admission, ${ }^{\dagger}$ Disinfection and sterilization of medical equipment/instruments.

Table 4. Results of the Korean National IPC survey corresponding to CC2, CC7, and CC8 of WHO IPCAF

\begin{tabular}{|c|c|c|c|c|c|}
\hline \multirow{2}{*}{$\begin{array}{l}\text { Korean national IPC } \\
\text { survey questions }\end{array}$} & \multirow[t]{2}{*}{ Answer } & \multicolumn{4}{|c|}{ Number (\%) } \\
\hline & & $\begin{array}{l}\text { Tertiary } \\
\text { hospital } \\
(n=42)\end{array}$ & $\begin{array}{l}\text { General } \\
\text { hospital } \\
(n=260)\end{array}$ & $\begin{array}{l}\text { Hospital } \\
(n=167)\end{array}$ & $\begin{array}{l}\text { Long- } \\
\text { term care } \\
\text { hospital } \\
(n=973)\end{array}$ \\
\hline \multicolumn{6}{|c|}{ Corresponding IPCAF core component : Core Component 2 (IPC guidelines) } \\
\hline \multirow[t]{3}{*}{$\begin{array}{l}\text { Availability of a } \\
\text { guideline for: }\end{array}$} & $\begin{array}{l}\text { Antibiotic } \\
\text { stewardship }\end{array}$ & 42(100.0) & $171(65.7)$ & $86(51.5)$ & $302(31.0)$ \\
\hline & $\begin{array}{l}\text { Disinfection and } \\
\text { sterilization }^{*}\end{array}$ & $42(100.0)$ & 251(96.5) & 123(73.6) & $889(91.3)$ \\
\hline & $\begin{array}{l}\text { Environmental } \\
\text { cleaning }\end{array}$ & 42(100.0) & 249(95.8) & 120(71.9) & DNA \\
\hline
\end{tabular}

Corresponding IPCAF core component : Core Component 7 (Workload, staffing and bed occupancy)

$\begin{array}{llllll}\begin{array}{l}\text { Bed spacing in ICU } \\ \text { (meters) }\end{array} & \begin{array}{l}\text { Average distance } \\ \text { between patient beds }\end{array} & 1.8 & 1.6 & \text { DNA } & \text { DNA }\end{array}$

Core Component 8 (Built environment, materials, and equipment for IPC)

$\begin{array}{llllll}\text { Hand hygiene stations } & \begin{array}{l}\text { Number of patients } \\ \text { sharing a hand } \\ \text { hygiene station }\end{array} & 1.6 & 2.8 & 4.1 & 6.8\end{array}$

\begin{tabular}{|c|c|c|c|c|c|}
\hline Isolation rooms in ER & $\begin{array}{l}\text { Average number of } \\
\text { negative pressure } \\
\text { isolation rooms in ER }\end{array}$ & 2.4 & 0.6 & DNA & DNA \\
\hline \multirow{3}{*}{$\begin{array}{l}\text { Injection safety: area } \\
\text { where fluid/injections } \\
\text { are prepared before } \\
\text { administration }^{+}\end{array}$} & $\begin{array}{l}\text { Sterile compound/ } \\
\text { clean rooms }\end{array}$ & $10(23.8)$ & $9(3.5)$ & $1(0.6)$ & $11(1.1)$ \\
\hline & $\begin{array}{l}\text { Dedicated/separate } \\
\text { preparation area in } \\
\text { wards }\end{array}$ & $28(66.7)$ & $167(64.2)$ & $116(69.5)$ & $483(49.6)$ \\
\hline & Other areas ${ }^{\ddagger}$ & $4(9.5)$ & $84(32.3)$ & $50(29.9)$ & $479(49.3)$ \\
\hline
\end{tabular}

$I P C$, Infection prevention and control; $C C$, Core component; WHO, World Health Organization; IPCAF, Infection Prevention and Control Assessment Framework; DNA, Data not available (due to the small number of hospitals that operate either ER and/or ICU in this hospital group); PPE, Personal protection 
equipment, ICU, Intensive care unit; $E R$, Emergency room. 'Disinfection and sterilization of medical equipment/instruments, ${ }^{\dagger}$ Indicator exclusive to the Korean National Infection Prevention and Control survey but relevant to the core component 8 of IPCAF, ${ }^{\ddagger}$ Shared, a non-dedicated area in wards, bedsides, etc.

\section{Supplementary Files}

This is a list of supplementary files associated with this preprint. Click to download.

- Additionalfile12.docx 